\title{
Molecular identification of oral microflora associated with different health conditions
}

\author{
Mohammed Alassiri'1, Mohamed Abu-Zeid', Mohammed H. Mutwakil1 1, Mohamed Morsi M. Ahmed*1,2 \\ 1Department of Biological Sciences, Faculty of Sciences, P.O. Box 80203, King Abdulaziz University, Jeddah City, 21589, Kingdom of Saudi Arabia \\ 2Nucleic Acids Research Department, Genetic Engineering and Biotechnology Research Institute (GEBRI), Mubarak City for Scientific Research and \\ Technological Applications. Alexandria City, Egypt
}

Correspondence Author: Mohamed Morsi M. Ahmed. Department of Biological Sciences, Faculty of Sciences, P.0. Box 80203, King Abdulaziz University, Jeddah City, 21589, Kingdom of Saudi Arabia

E-mail: mmmahmed6@yahoo.ca

Received date: 29 August 2019, Accepted date: 28 October 2019, Online date: 30 October 2019

Copyright: (C) 2019 Mohammed Alassiri. This is an open-access article distributed under the terms of the Creative Commons Attribution License, which permits unrestricted use, distribution, and reproduction in any medium, provided the original author and source are credited.

\begin{abstract}
The current study aims to detect and identify microbes in human saliva microbiota of medical students and employees and correlate species with health conditions, smokers (S), influenza infected (I) and normal group (N). A total number of 100 samples were collected from medical school male students and employees' volunteers at Jeddah, Saudi Arabia in March 2017. The molecular 16S rRNA gene sequencing indicated a broad diversity of bacteria representing two different phyla; Firmicutes such as Staphylococcus and Proteobacteria such as Klebsiella species. High dominance among the identified genera of Staphylococci $30 \%$, followed by Klebsiella $15 \%$, while unculturable species showed $50 \%$ dominancy. There was a $100 \%$ correlation of the genera Klebsiella with smokers' group. Staphylococci genera which were dominant in the normal and influenza-infected group disappeared completely in the smoker's group. Comparing the morphology data observed with molecular 16S rRNA identities, the results were in agreement with the genera identified. Our study suggests that smoking alters bacterial acquisition and oral mucosal colonization in favor of periodontal pathogens. Awareness should be created for the public on the health implication of smoking and poor oral practice.
\end{abstract}

Keywords: Oral; Microbiota; Influenza; Smokers; oropharynx

\section{INTRODUCTION}

To various types of environmental bacteria, the human oropharynx is constantly exposed, primarily from inhaled dust, ingested food, and water. The human oral cavity may be exposed to various types of environmental microorganisms inhaled by air, drinking water, and ingested meat. The oral cavity is an ideal location for some commensal microbes (e.g. Neisseria spp. and Streptococcus spp.). Certain parts of the body can be infected by diseases. Normal flora prevents colonization among people in good health by invading the body by changing $\mathrm{pH}$, In the production of bacteriocins and in the formation of a barrier system that prevents adhesion to the mucosal surface [1].

Microorganisms that cannot be prevented in our atmosphere are sometimes introduced into the mouth cavity using contaminated material due to improper activity, such as; tobacco, contaminated food, water, brushing teeth, etc. [2]. Several pathogenic microbes like; Streptococcus pyogenes, Staphylococcus aureus, species Bacillus, Escherichia coli, Pseudomonas aeruginosa, Candida, Entamoeba gingival is and species Prohormones gingival may be present in the mouth cavity due to poor mouth hygiene [1]. Such microbes can cause diseases and disorders such as gingivitis, pharyngitis, stomatitis, tonsillitis, sinusitis, decay of the tooth, oral thrush, halitosis, oral cancer, etc. [3]. Despite warnings against cancer and other related diseases, the number of smokers in our country will increase, but the microbial profile of the oral cavity for cigarettes in our population is unknown. Due to poor oral hygiene measures among smokers and non-smokers, the treatment of oral cavities awaiting homework is not taken seriously. Given these rapid advances, little information is available on the effect of acute viral infection on the structure, kinetics, and quantity of microbiota diner at a welcome place. Changes in the bacterial influenza-related group structure can explain the increased risk of pneumonia and bacterial otitis media following an influenza virus infection [4]. Organisms responsible for bacterial pneumonia and otitis media detect the rise in respiratory abundance at the highest levels after respiratory virus infection more commonly $[5,6]$. Adults previously diagnosed with the influenza virus have an expanded nose port Influenza virus-infected adult with elevated nose/ throat port Streptococcus pneumonia and Staphylococcus aureus were 
only shown in the United States [5]. Nevertheless, there was no evidence of interaction between the microbiota of the nose/ throat and the threat of influenza in human populations.

The objective of this research is to detect and identify the microbes found in the microbiota in the human saliva of groups routinely infected with influenza $(\mathrm{I})$, smoking $(\mathrm{S})$ and healthy $(\mathrm{N})$ viruses using phenotypes, gram staining, and molecular techniques using $16 \mathrm{~S}$ gene sequencing. This research would explain the potential effects of smoking and influenza infection on oral health in our subjects.

\section{Sampling and phenotypic characterization}

\section{MATERIALS AND METHODS}

A total number of 100 samples were collected from medical school male students and employees' volunteers at Jeddah, Saudi Arabia, in March 2017. The samples consisted of 20 - 22-year-old students and 24 - 31-year-old employees having 10\% smokers and $5 \%$ with respiratory indisposition (regular flue). Samples were collected from the mouth by rolling a sterile cotton swab across the gingival region and the roof and floor of the oral cavity. Swabs were submerged in $1 \mathrm{ml}$ sterile nutrient and blood broths and mixed vigorously to generate a suspension of microbiome-associated bacteria. Aliquots of this suspension were inoculated onto two types of bacteriological agar, firstly nutrient agar, and secondly blood agar medium. Triplicates of each medium were inoculated and incubated under $37^{\circ} \mathrm{C}$ in the anaerobic atmosphere. All cultures were checked every day for up to 4 days for the presence of bacterial colonies. If present, colonies were picked from primary isolation plates and passaged onto new media and re-incubated under the same conditions. The second passage isolates obtained in this manner were transferred to cryovials containing the above-specified broths $+10 \%(\mathrm{v} / \mathrm{v})$ glycerol and stored at $-80^{\circ} \mathrm{C}$ until required. Isolates were provisionally identified based on their colonial morphology and Gram staining. In total, 26 individual isolates were transferred to fresh plates three times and then processed for sequencing of $16 S \mathrm{rRNA}$.

\section{Genomic extraction and 16S rRNA gene amplification}

The entire DNA of the genome was extracted as directed by the manufacturer. The genomic DNA purification kit of QIAamp (QIAGEN) was used for genome DNA extraction. In short, cells are released enzymatically from the DNA. The columns were prepared, and centrifugation washed the DNA. Instead, with an elution buffer, the DNA was eluted, centrifuged and stored in a collector tube [7].

The primers used to amplify the $16 \mathrm{~S}$ rRNA for bacteria and other microbes were $27 \mathrm{~F}$ and $1492 \mathrm{R}$ [8], respectively. The PCR reaction was performed with $20 \mathrm{ng}$ of genomic DNA as the template in a $30-\mathrm{mL}$ reaction mixture by using EF-Taq DNA polymerase (Solgent, Korea). The thermocycler conditions were $95^{\circ} \mathrm{C}$ for $5 \mathrm{~min}$, followed by 35 cycles of $95^{\circ} \mathrm{C}$ for $2 \mathrm{~min}, 55^{\circ} \mathrm{C}$ for $60 \mathrm{~s}$, and $72^{\circ} \mathrm{C}$ for $60 \mathrm{~s}$, a final for extension $\left(10 \mathrm{~min}\right.$ at $72^{\circ} \mathrm{C}$. After that, the amplification products were purified using a multiscreen filter plate (Millipore Corp., Bedford, MA, USA). Sequencing reactions were performed using a PRISM BigDye Terminator v3.1 Cycle Sequencing Kit (Applied Biosystems, Foster City, Calif., USA). The mixture was incubated at $95^{\circ} \mathrm{C}$ for 5 min followed by 5 min on ice, and then analyzed using an ABI Prism 3730XL DNA analyzer (Applied Biosystems, Foster City, CA). The DNA sequencing of isolates was performed by Macrogen Inc. (Seoul, Korea).

\section{Microbial phylogeny \\ Results and discussion \\ Isolation and phenotypic characterization of oral bacteria}

Phylogenetic trees were constructed using neighbour-joining [9 ] with MEGA5 for Windows [10]. Evolutionary distances were calculated with the Kimura 2-parameter method. Bootstrap analyses of the neighbour-joining data were conducted based on 1000 samples to assess the support for inferred phylogenetic relationships.

The present study aims to detect and identify microbes in human saliva microbiota of regular influenza-infected group (I), smokers' group (S) and normal group (N) of medical school male students and employees' volunteers at Jeddah, Saudi Arabia using phenotypes, gram stain, and molecular techniques. Most colonies appear relatively smooth and glossy. Colonies of most strains are usually opaque and may be pigmented white or cream and sometimes yellow to orange. Gram staining results indicated $72 \%$ of samples are gram-positive, spherical cocci grape like-cluster. The second group contained $16 \%$ of the gramnegative rod-shaped bacterium. The third group consisted of $8 \%$ gram-positive rods, and the fourth group comprised $4 \%$ gramnegative diplococci colonies as illustrated in Figure 1.

There was no statistically significant difference between the selected ages of students $(20-22$ years old $)$ and employees ( 24 - 31 years old) for the morphologically identified colonies as shown in Figure 1 . This could explain the phenomenon that the ages used in the current experiment do not show a significant effect on the oral microbiome. In another word, human been ecological behavior during aging may influence the microbiome structure due to many environmental factors such as smoking and oral diseases. Therefore, spaced age interval could reveal significant differences among microbiome of normal groups.

The range of colony morphologies obtained in this study provided a simple but nonetheless immediate indication that the oral microbiome includes a functional diversity of cultivatable micro-organisms. The use of selective media and different culture

conditions helped to increase the diversity of colonial morphologies obtained. The isolates obtained were characterized on the 
basis of colonial morphology, microscopic appearance of Gram-stained smears and comparative analysis of partial 16S rRNA sequences obtained using Sanger sequencing of PCR products. There was no statistically significant difference between the selected ages of students $(20-22$ years old) and employees $(24-31$ years old) for the morphologically identified colonies. Though a direct comparison of studies is not possible due to different methodologies, the bacterial profiles in the elderly are more diverse (i.e., have more species) than those of the normal flora of healthy young and middle-aged adults [11]. It has been suggested that age-related changes in the immune response may result in a higher oral bacterial diversity in the elderly [12]. Only subjects with relatively good oral health, including the absence of root caries, were included in the present study. It is known that root caries has a significant association with poor oral hygiene [13].

\section{Molecular identification of bacterial isolates}

After sequencing of the $16 \mathrm{~S}$ rRNA gene, data were submitted to the genetic Sequence database at the National Center for Biotechnology Information (NCBI). The GenBank ID of these strains is indicated in Table 1. BLAST analysis of each unambiguous sequence yielded high sequence similarities (>90\%) with GenBank submissions (Table 1) and allowed 16 of the isolates to be characterized to species level with confidence; while 10 isolates consequences were unculturable isolates. However, for others, four isolates species identification was not possible as their partial $16 \mathrm{~S}$ rDNA sequences were indistinguishable from those of multiple taxa. Broad diversity of bacteria was characterized, including representatives of two different bacterial phyla; Firmicutes such as Staphylococcus, Proteobacteria such as Klebsiella species. Table 1 indicated high dominance among the identified genera of Staphylococci 30\%, followed by Klebsiella 15\%, while unculturable species showed $50 \%$ dominancy. The health conditions normal, influenza and smokers were associated with the bacterial isolate in Table 1.

Figure 2 showed significant high species variation compared to smokers and influenza-infected groups which might explain the influence of health conditions on the microbiome variation. There was a 100\% correlation of the genera Klebsiella with smoker's group as shown in Figure 2. Staphylococci genera which were dominant in the normal and influenza-infected group disappeared completely in the smokers' group which may be indicated that smoking habit contributed to microbiome shifting to overwhelm or cope with smoking toxicity. On the other hand, the distribution of Staphylococci genera between the standard and influenzainfected group showed high diversity in the normal group than the infected one throughout shifting species in the same genera. For example, Staphylococcus warneri was detected only in the infected group, while the other Staphylococcus species were observed in the normal group. This could explain the phenomenon that in disease condition the biological system needs more energy to cope with illness. Therefore, the microbiome makes dominancy for species in the same genera which can balance the biological system's energy during indisposition. The isolation frequencies in the present report were relatively similar compared with previous studies that reported frequencies of $60 \%$ in saliva and $17 \%$ in dental plaque from healthy subjects aged $20-39$ years old [14], $43 \%$ in plaque from healthy subjects [15] and $50 \%$ in those with gingivitis and periodontitis [16]. Although the reason is unclear, it may require more significant amounts of oral samples for an accurate count of viable cellular staphylococci in selective media. Moreover, comparing the data observed in Table 1. with molecular 16S rRNA identities and literature morphology of bacteria, the results agreed with the genera identified.

The unculturable bacterial species which represents $50 \%$ of the identified isolates, had been looked up in the gene bank seeking low percentage confidence identity. One isolate represents Neisseria genera and the other represented Streptococci with low percentage confidence; however, all the different species represented staphylococci. This could be noticed in the phylogenetic relationship among the bacterial species indicated in Figure 3. The problem with low confidence is because the 16S rRNA sequencing machinery had been conducted in one direction instead of the bidirectional one.

The phylogenetic tree of these four $16 \mathrm{~S}$ rRNA gene sequences indicated in table 1. was constructed against each other as shown in Figure 3. The major families were Staphylococci and Klebsiella which comprised 11 species and 3 species respectively. The other diverse family was unculturable species involved of ten species. Closely related Staphylococci genera (18 species including unculturable isolates) with high phylogenetic relationship to each other. The other genera included Klebsiella species were in the same cluster as shown in Figure 3.

In general, the results of these three approaches concurred, although the unculturable isolates showed a low level of confidence identity for the genera Klebsiella and Streptococci. This may be due to the need for higher samples to be processed. The identities of the organisms isolated in this study were generally in line with what has been encountered in previous studies. Three genera were encountered most frequently ( 3 of 15 sequences each). Comparison of these data with the phenotypic data for the isolates for which was obtained as unambiguous $16 \mathrm{~S}$ rDNA data suggests that Staphylococcus species were the most common taxon isolated 11 confirmed and 7 putative isolates among the 26 isolates obtained). Staphylococci are mainly harbored on the skin, as well as skin glands and mucous membranes in humans. Although these micro-organisms are considered to be transiently resident in the oral cavity $[14,17]$, previous studies have found that the occurrence of Staphylococcus epidermidis was significantly high in saliva from healthy adults[18]. This finding led to the speculation that some of the causative staphylococci originated in the oral cavity.

In this analysis, low microbe variability was recovered from smokers ' oral cavity by $16 \%$ compared to non-smokers by $72 \%$. This result contradicts that Kubota, Tanno-Nakanishi [19] stated that the level of detection of periodontopathic bacteria in smokers was higher. Nevertheless, it agrees with that reported by Sreedevi, Ramesh [20]. They said there was no difference between smokers and non-smokers in the periodontal microbiota status. The disparity may be due to the sample forms of analysis. The women were not included in the study because our city's women did not accept the usual thing.

For the same reason and to avoid potential hormone-induced microcirculatory changes, another study omitted female participants from their research. In this study, the most prevalent bacteria among smokers was the Klebsiella species (16\%), 
while the dominant Staphylococcus aureus (72\%) was more prevalent among non-smokers. Our results differ slightly from Wetzel's study, Schaumburg (3) as the most common among smokers isolates Streptococcus mutants, Staphylococcus aureus, and Pseudomonas aeruginosa. The slight change in our subjects ' microbial plant may be due to changes in patterns of oral hygiene. The isolates of this analysis, as well as the mouth cavity, are the pathogenic potential or opportunistic pathogen of the up and down respiratory channels. When comparing smokers ' microflora mouth with non-smokers, we found a $100 \%$ difference in oral microbiota that has a good community transition range for Gram-negative bacteria dominated by Gram-positive to negative. Similarly, another study showed that Staphylococcus aureus and Gram-negative species were more prevalent among smokers, including; Klebsiella pneumonia, Pseudomonas aeruginosa and Serratia marcescens. Not related to non-smokers were the species of Serratia marcescens and Citrobacter. Escherichia coli, Streptococcus, and Candida species have been well distributed in both groups and are possibly part of the mouth cavity's microflora core [21]. Smoking is related to a number of changes in the mouth's mucous membranes. While our participants have not examined the impact of cigarette exposure, smokers have had more diseases and disorders of the mouth than non-smokers. The most common oral disease among smokers was dental degradation, accompanied by halitosis (bad breath). It was a mixture of oral cavity disease and microbial isolates among smokers that was statistically significant [21]. It indicates that oral microbial development and oral cavity disorders are influenced by smoking. Among smokers, mouth ulcers and blackened teeth were more common than non-smokers. Ulceration in smokers may be caused by the proliferation and invasion of the mucosal mouth by species introduced by cigarette sticks or the reduction of the usual oral plant by smoke, leaving opportunistic prosperity opportunities [21].

Table 1: 16S rRNA sequence similarities of 26 oral isolates.

\begin{tabular}{|c|c|c|c|}
\hline Sample Code & $\begin{array}{l}\text { Health } \\
\text { Condition }\end{array}$ & $\begin{array}{l}\text { Taxa sharing highest sequence } \\
\text { similarity }\end{array}$ & $\begin{array}{l}\text { GenBank } \\
\text { Accession }\end{array}$ \\
\hline $\mathbf{C 1 3}$ & Normal & Uncultured bacterium & AY939303.1 \\
\hline G13 & Normal & Bacterium 7-II & KF303138.1 \\
\hline K13 & Normal & Staphylococcus pasteuri & KT003275.1 \\
\hline 013 & Normal & Uncultured bacterium & JN698671.1 \\
\hline C15 & Normal & Staphylococcus aureus & MF157603.1 \\
\hline G15 & Normal & Staphylococcus sp. & EU807751.1 \\
\hline M15 & Normal & Uncultured bacterium & JF146682.1 \\
\hline C17 & Normal & Staphylococcus aureus & MF157603.1 \\
\hline G17 & Normal & Uncultured bacterium & JF146682.1 \\
\hline I17 & Normal & Staphylococcus aureus & KX821630.1 \\
\hline K17 & Normal & Uncultured bacterium & KY969986.1 \\
\hline M17 & Normal & Staphylococcus epidermidis & FJ613559.1 \\
\hline A19 & Normal & Uncultured bacterium & JF208300.1 \\
\hline E19 & Normal & Staphylococcus aureus & LT689037.1 \\
\hline G19 & Normal & Staphylococcus aureus & KP728240.1 \\
\hline K19 & Normal & Uncultured bacterium & GQ110672.1 \\
\hline M19 & Normal & Staphylococcus sp. & JF421690.1 \\
\hline K15 & Smoking & Klebsiella sp. & KJ803943.1 \\
\hline 015 & Smoking & Klebsiella pneumoniae & KU937377.1 \\
\hline E17 & Smoking & Klebsiella variicola & KC853296.1 \\
\hline 017 & Smoking & Klebsiella pneumoniae & KX636139.1 \\
\hline
\end{tabular}


Citation: Mohammed Alassiri et al, 2019. Molecular identification of oral microflora associated with different health conditions. Advances in Environmental Biology., 13(10): 36-44.DOI:10.22587/aeb.2019.13.10.5

\begin{tabular}{cccc}
\hline $\mathbf{A 1 3}$ & Influenza & Staphylococcus warneri & KX449240.1 \\
\hline $\mathbf{I 1 3}$ & Influenza & Uncultured bacterium & JQ454352.1 \\
\hline $\mathbf{E 1 5}$ & Influenza & Uncultured bacterium & KF660615.1 \\
\hline $\mathbf{A 1 7}$ & Influenza & Uncultured bacterium & JF188967.1 \\
\hline $\mathbf{C 1 9}$ & Influenza & Staphylococcus sp. & KF648901.1 \\
\hline
\end{tabular}

Table 2: Details of the incubation conditions, colonial and microscopic appearance of isolates obtained from oral swabs in this study.

\section{No. (\%) Genus Morphology Colony Morphology Microscopic Observation}

172 Staphylococcus $\begin{gathered}\text { Gram +ve } \\ \text { Cocci Cluster }\end{gathered}$

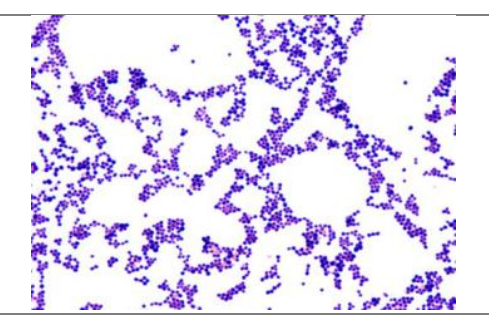

$2 \quad 16 \quad$ Klebsiella $\quad \begin{gathered}\text { Gram -ve } \\ \text { Rods Mucoid }\end{gathered}$
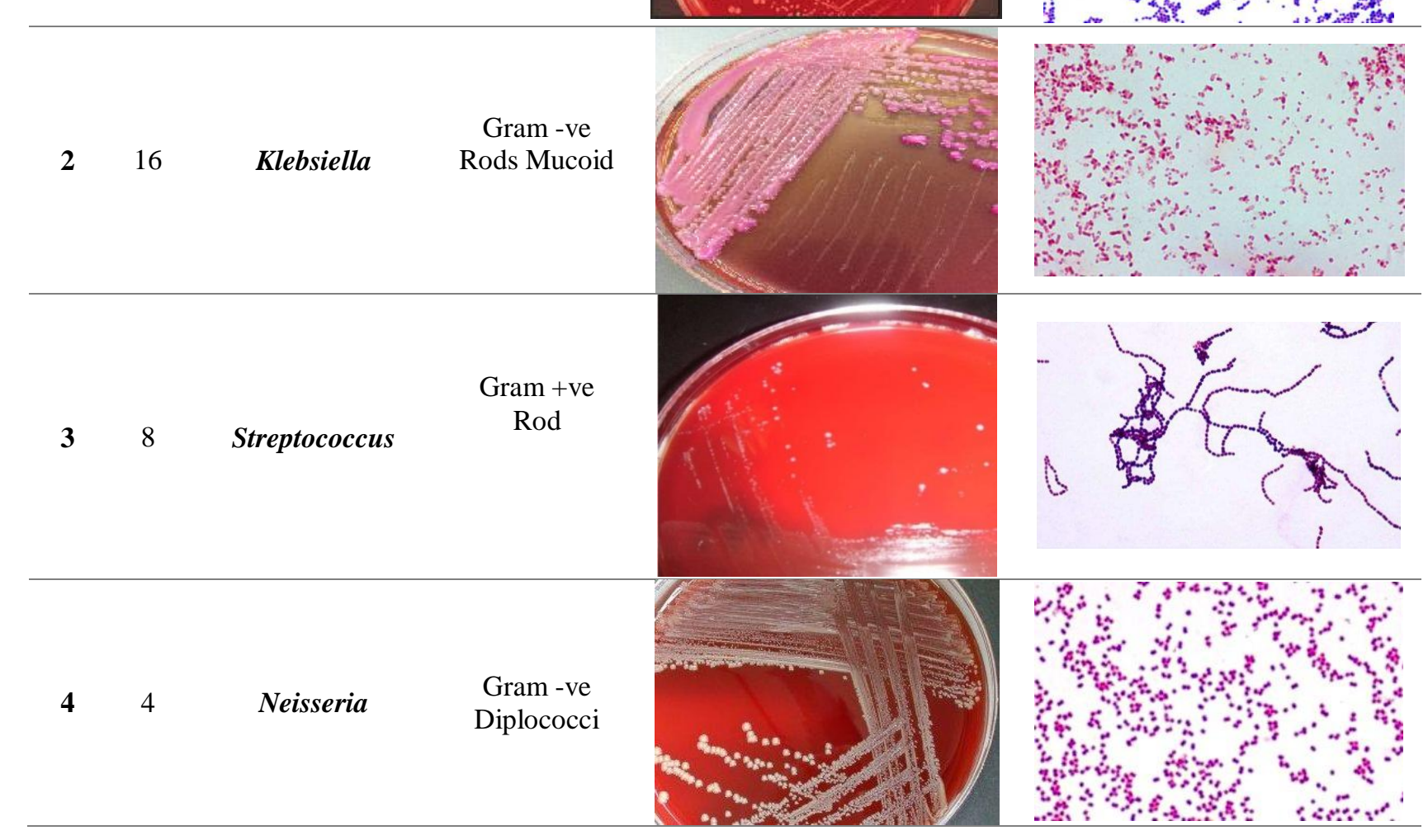


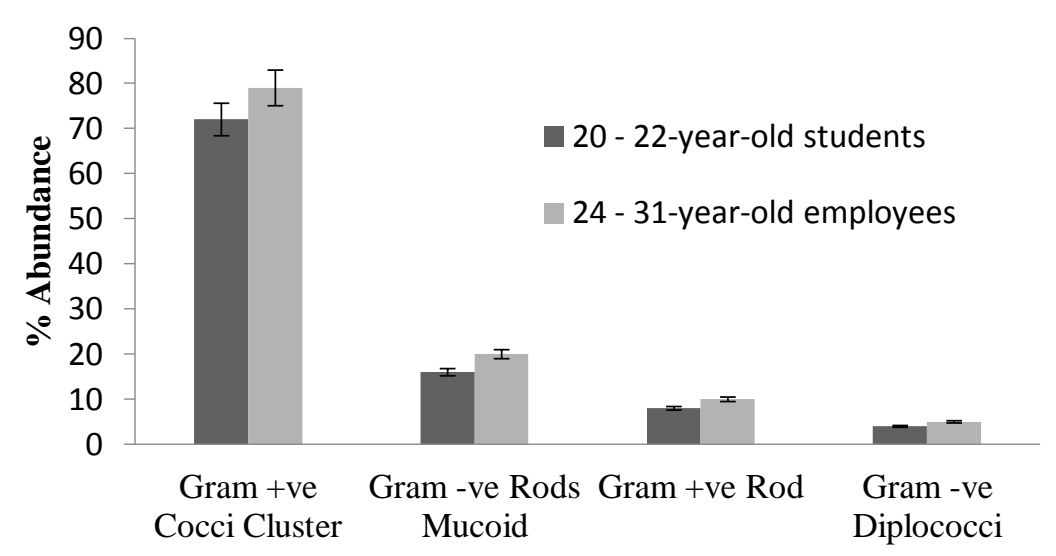

Fig. 1: Morphological characters of the oral microbiome.

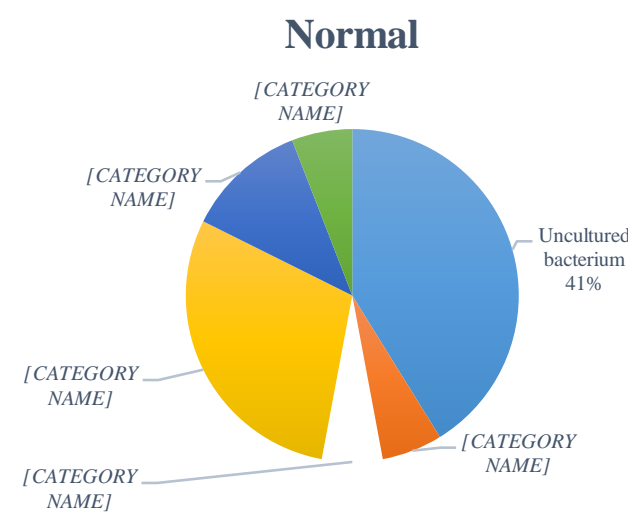

A

Infected

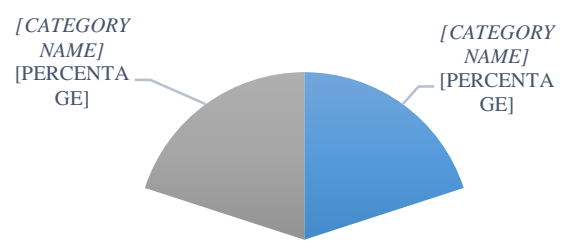

B

Uncultured

bacterium
$60 \%$

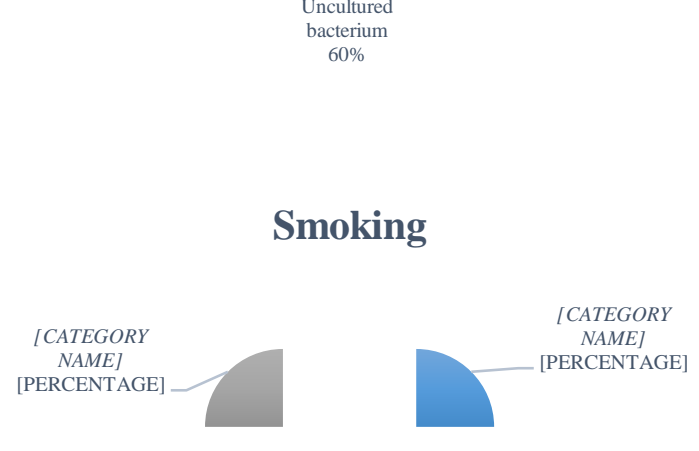

C

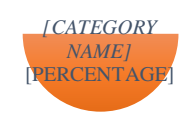

Fig. 2: Oral microbiome parametric analysis of smokers, influenza and normal groups. 


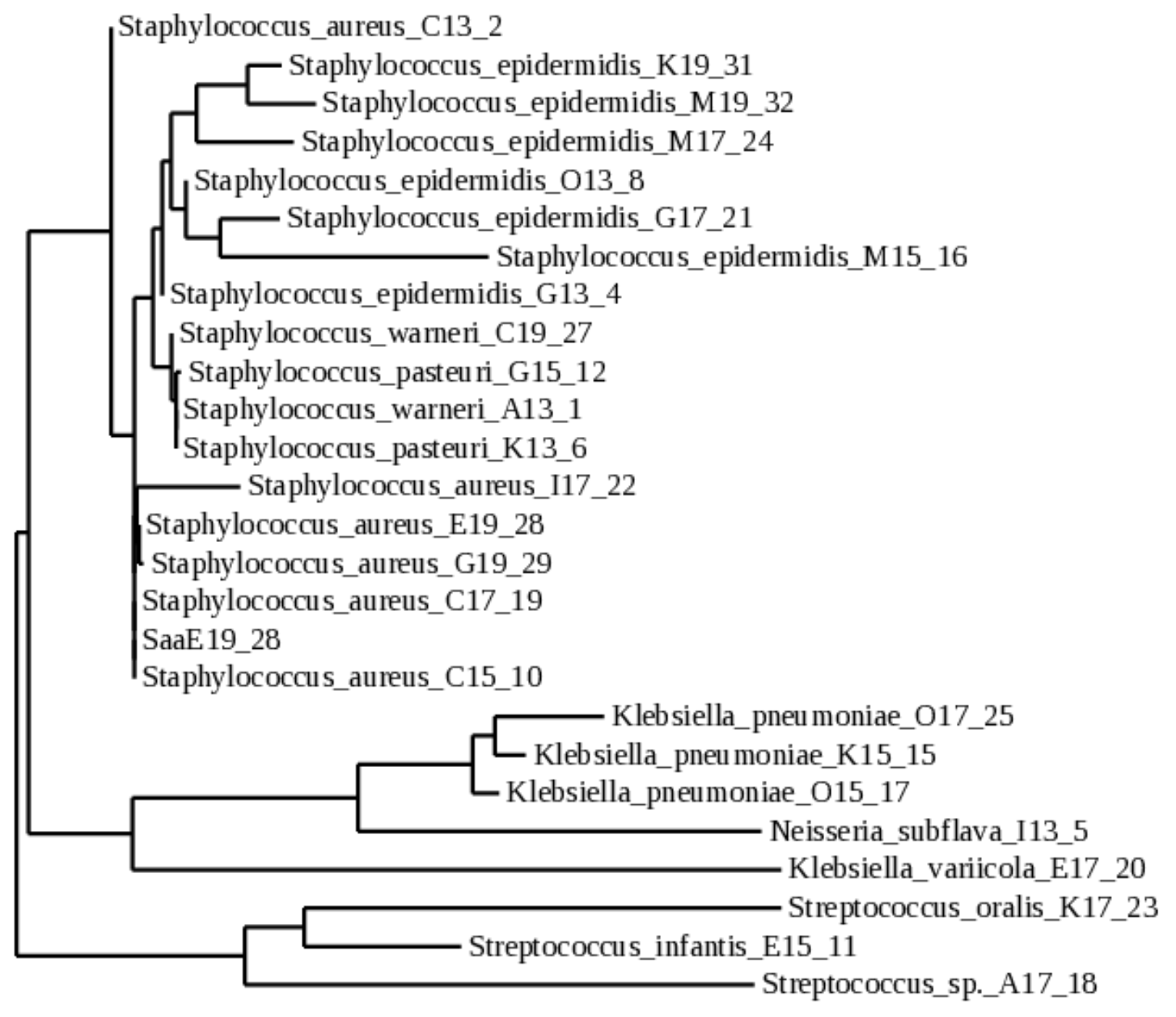

0.2

Fig. 3: Comparative phylogenetic analysis of the oral isolates Staphylococci and Klebsiella from GenBank.

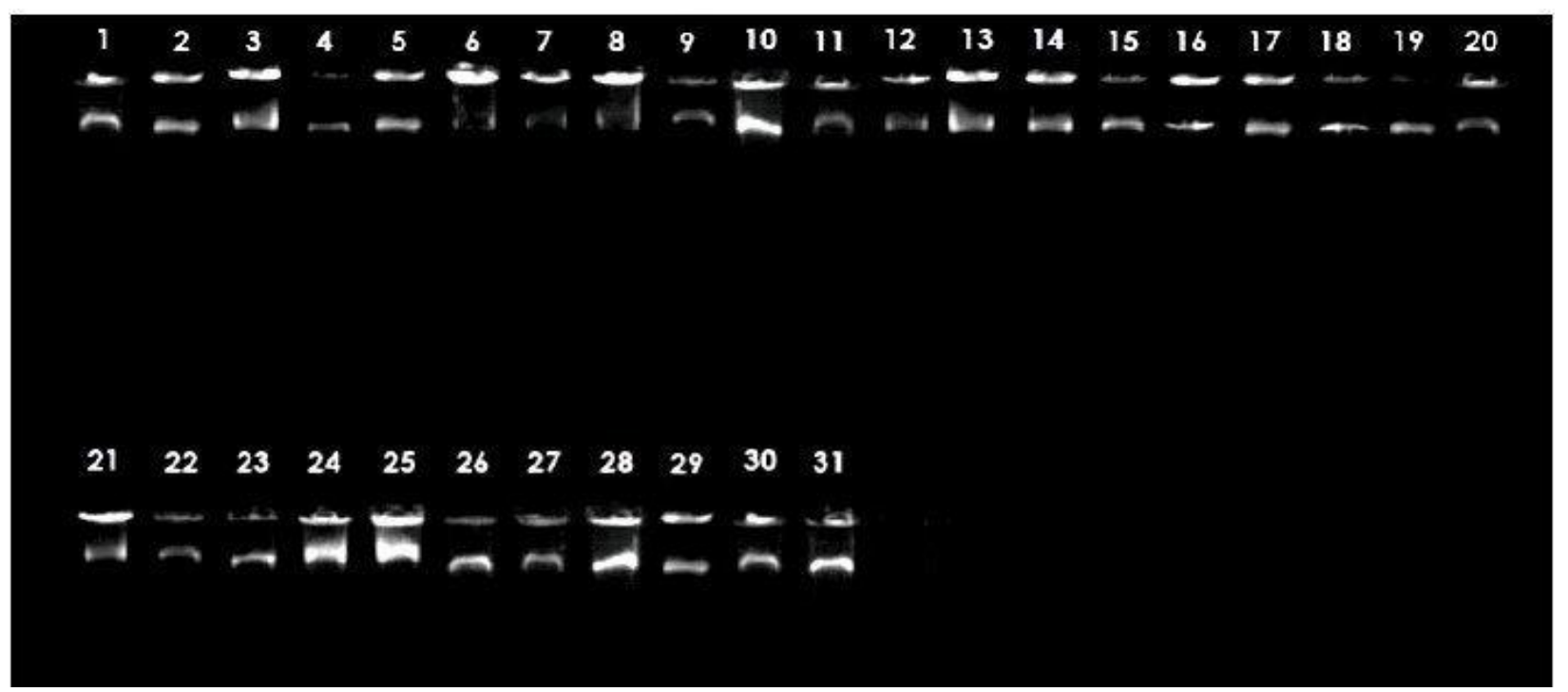

Fig. 4: DNA molecular electrophoresis of isolated oral bacteria.

There was no significant alteration in microbiome composition for the influenza-infected group compared to the smokers and normal groups. Staphylococci genera which were dominant in the normal and influenza-infected group disappeared completely in the smoker's group. This study explains human population prospection relationship between the nose/throat microbiome and influenza virus infection. Another study demonstrated that influenza susceptibility is associated with differences in the overall bacterial community structure after adjusting for potential confounders [22]. The exact biological mechanisms are 
still unknown, but few murine studies that investigate this relationship may suggest that immunomodulation causes it. If there is a causal relationship between the microbiome and influenza, the results suggest that the microbiome may lead to an increased risk of influenza among the classes. The use of clustered specimens of the nose and throat is a drawback of the study. When the sampling is related to both the observed bacterial population structure and the susceptibility to influenza, a different field sampling can cause bias. Although reliable sampling techniques have minimized this among all study participants, Factors such as age can affect associations and explain age-related differences in the structure of the group. Bacterial While much work is needed to translate these findings into potential public health and public health policies, these results lead to literature indicating that the microbiome can be controlled and reduced the risk of infection [23, 24]. Every year, the influenza virus is one of the leading causes of severe disease and death [25,26]. Nevertheless, the efficacy of vaccines varies by year [27] and there is still much debate about the use of antivirals for prophylaxis, especially to prevent asymptomatic infections and transmission of influenza [28]. Our study suggests further analysis of the microbiome as a potential target for reducing the risk of influenza.

Staphylococci are normal nasal flora residents [29, 30], so they can travel through the mouth reliably. It is also possible to contaminate skin flora. Additionally, it may be limited in a person to the number of native staphylococcus strains. Such results may survive oral flowering of Staphylococcus species found in the oral cavity, even though they may be collected from the nasal cavity continuously. The levels of occurrence of staphylococci in saliva increase with age, according to another study [14], Staphylococci occurrence levels increase with age in saliva.

Smokers had a diverse population of microbes compared to non-smokers. Our study suggests that smoking in favor of paradental infections affects bacterial acquisition and oral mucosal colonization. Awareness of the health implications of cigarettes and bad oral communication should be developed for the public. In view of the above deficiencies, bacteria are described using molecular methods. 16S rDNA sequence analysis is a fast and reliable method for the identification of oral bacteria. Many closely related bacteria, however, can show high identity in their sequences of 16S rDNA.

\section{Conflict of interest}

The authors declare no conflicts of interest.

\section{Acknowledgment}

This work was supported by King Abdulaziz City for Sciences and Technologies (KACST) in Saudi Arabia 1-17-01-009-0025. Also, the authors acknowledge assistance from Sciences \& Technology Unit, Deanship of Scientific Research, Deanship of Graduate Studies, and acknowledge support from the Dept. of Biology, Faculty of Sciences, King Abdulaziz University (KAU), Jeddah City, KSA.

\section{References}

1. Baron S. Alphaviruses (Togaviridae) and Flaviviruses (Flaviviridae)--Medical Microbiology: University of Texas Medical Branch at Galveston; 1996.

2. Saini R, Saini S. Microbial flora on toothbrush - At greater risk. Ann Nigerian Med Annals of Nigerian Medicine. 2010;4(1):31.

3. Wetzel WE, Schaumburg C, Ansari F, Kroeger T, Sziegoleit A. Microbial contamination of toothbrushes with different principles of filament anchoring. Journal of the American Dental Association (1939). 2005;136(6):758-65.

4. . .!!! INVALID CITATION !!! .

5. V DEL, Malosh R, Ramadugu K, Srinivasan U, Dawid S, Ohmit S, et al. Co-colonization by Streptococcus pneumoniae and Staphylococcus aureus in the throat during acute respiratory illnesses. Epidemiol Infect. 2016;144(16):3507-19.

6. Fan RR, Howard LM, Griffin MR, Edwards KM, Zhu Y, Williams JV, et al. Nasopharyngeal Pneumococcal Density and Evolution of Acute Respiratory Illnesses in Young Children, Peru, 2009-2011. Emerg Infect Dis. 2016;22(11):1996-9.

7. Iacono ML, Monica V, Righi L, Grosso F, Libener R, Vatrano S, et al. Targeted next-generation sequencing of cancer genes in advanced stage malignant pleural mesothelioma: a retrospective study. Journal of thoracic oncology. 2015;10(3):492-9.

8. Stackebrandt E, Goodfellow M. Nucleic acid techniques in bacterial systematics: Wiley; 1991.

9. Saitou N, Nei M. The neighbor-joining method: a new method for reconstructing phylogenetic trees. Mol Biol Evol. 1987;4(4):406-25.

10. Tamura K, Peterson D, Peterson N, Stecher G, Nei M, Kumar S. MEGA5: Molecular Evolutionary Genetics Analysis Using Maximum Likelihood, Evolutionary Distance, and Maximum Parsimony Methods. Molecular Biology and Evolution Molecular Biology and Evolution. 2011;28(10):2731-9.

11. Aas JA, Paster BJ, Stokes LN, Olsen I, Dewhirst FE. Defining the normal bacterial flora of the oral cavity. J Clin Microbiol. 2005;43(11):5721-32.

12. Marsh PD, Percival RS. The oral microflora--friend or foe? Can we decide? Int Dent J. 2006;56(4):233-9.

13. Simons D, Kidd EAM, Beighton D. Oral health of elderly occupants in residential homes. The Lancet The Lancet. 1999;353(9166):1761. 
14. Percival R, Challacombe S, Marsh P. Age-related microbiological changes in the salivary and plaque microflora of healthy adults. J Med Microbiol. 1991;35(1):5-11.

15. Murdoch FE, Sammons RL, Chapple IL. Isolation and characterization of subgingival staphylococci from periodontitis patients and controls. Oral Dis. 2004;10(3):155-62.

16. Rams TE, Feik D, Slots J. Staphylococci in human periodontal diseases. Oral Microbiol Immunol. 1990;5(1):29-32.

17. Marsh P, Martin M. Oral microbiology. Oxford; Boston, Mass: Wright; 1999.

18. Ikeda Y, Ohara-Nemoto Y, Kimura S, Ishibashi K, Kikuchi K. PCR-based identification of Staphylococcus epidermidis targeting gseA encoding the glutamic-acid-specific protease. Canadian Journal of Microbiology. 2004;50:493-8.

19. Kubota M, Tanno-Nakanishi M, Yamada S, Okuda K, Ishihara K. Effect of smoking on subgingival microflora of patients with periodontitis in Japan. BMC Oral Health. 2011;11.

20. Sreedevi M, Ramesh A, Dwarakanath C. Periodontal status in smokers and nonsmokers: A clinical, microbiological, and histopathological study. Int J Dent International Journal of Dentistry. 2012.

21. Ogba OM, Ewa JJ, Olorode OA, Mbah M. Effect of Tobacco Smoking on Oral Microbial Flora and the Relationship with Oral Health in Calabar, Nigeria. Development. 2017;4:5.

22. Lee KH, Gordon A, Shedden K, Kuan G, Ng S, Balmaseda A, et al. The respiratory microbiome and susceptibility to influenza virus infection. PLoS ONE PLOS ONE. 2019;14(1):e0207898.

23. Luoto R, Ruuskanen O, Waris M, Kalliomaki M, Salminen S, Isolauri E. Prebiotic and probiotic supplementation prevents rhinovirus infections in preterm infants: a randomized, placebo-controlled trial. J Allergy Clin Immunol. 2014;133(2):40513.

24. Panigrahi P, Parida S, Nanda NC, Satpathy R, Pradhan L, Chandel DS, et al. A randomized synbiotic trial to prevent sepsis among infants in rural India. Nature. 2017;548(7668):407-12.

25. Organization WH. Influenza. In: Immunization, vaccines and biologicals: influenza [Internet] [cited 17 Feb 2017] [Available from: Available: http://www.who.int/immunization/topics/influenza/en/.

26. Iuliano AD, Roguski KM, Chang HH, Muscatello DJ, Palekar R, Tempia S, et al. Estimates of global seasonal influenzaassociated respiratory mortality: a modelling study. Lancet. 2018;391(10127):1285-300.

27. Belongia EA, Simpson MD, King JP, Sundaram ME, Kelley NS, Osterholm MT, et al. Variable influenza vaccine effectiveness by subtype: a systematic review and meta-analysis of test-negative design studies. Lancet Infect Dis. 2016;16(8):942-51.

28. Jefferson T, Jones M, Doshi P, Spencer EA, Onakpoya I, Heneghan CJ. Oseltamivir for influenza in adults and children: systematic review of clinical study reports and summary of regulatory comments. Bmj. 2014;348:g2545.

29. Wenzel RP, Perl TM. The significance of nasal carriage of Staphylococcus aureus and the incidence of postoperative wound infection. J Hosp Infect. 1995;31(1):13-24.

30. Kluytmans J, van Belkum A, Verbrugh H. Nasal carriage of Staphylococcus aureus: epidemiology, underlying mechanisms, and associated risks. Clin Microbiol Rev. 1997;10(3):505-20.

31. Guclu E, Yavuz T, Tokmak A, Behcet M, Karali E, Ozturk O, et al. Nasal carriage of pathogenic bacteria in medical students: effects of clinic exposure on prevalence and antibiotic susceptibility. Eur Arch Otorhinolaryngol. 2007;264(1):858 . 